\title{
The effects of landscape patterns on ecosystem services: meta-analyses of landscape services
}

\author{
Gabriela Teixeira Duarte - Paloma Marques Santos • Tatiana Garabini Cornelissen • \\ Milton Cezar Ribeiro • Adriano Pereira Paglia
}

Received: 25 August 2017/Accepted: 19 June 2018/Published online: 25 June 2018

(C) Springer Nature B.V. 2018

\begin{abstract}
Purpose The recently introduced concept of 'landscape services'-ecosystem services influenced by landscape patterns-may be particularly useful in landscape planning by potentially increasing stakeholder participation and financial funding. However, integrating this concept remains challenging. In order to bypass this barrier, we must gain a greater understanding of how landscape composition and configuration influence the services provided.
\end{abstract}

Electronic supplementary material The online version of this article (https://doi.org/10.1007/s10980-018-0673-5) contains supplementary material, which is available to authorized users.

G. T. Duarte $(\bowtie)$ · P. M. Santos · A. P. Paglia

Laboratório de Ecologia e Conservação (LEC),

Departamento de Biologia Geral, Instituto de Ciências

Biológicas, Universidade Federal de Minas Gerais, Av.

Antônio Carlos, 6627, Belo Horizonte,

Minas Gerais 31270-901, Brazil

e-mail: gabitduarte@gmail.com

G. T. Duarte · P. M. Santos · M. C. Ribeiro

Laboratório de Ecologia Espacial e Conservação (LEEC), Departamento de Ecologia, Instituto de Biociências, Universidade Estadual Paulista - UNESP, Av. 24A, 1515, Rio Claro, São Paulo 13506-900, Brazil

T. G. Cornelissen

Laboratório de Ecologia Vegetal e Interações (LEVIN), Departamento de Ciências Naturais, Universidade Federal de São João Del-Rei, Praça Dom Helvécio, 74 Fábricas, São João Del-Rei, Minas Gerais 36301-160, Brazil
Methods We conducted meta-analyses that considered published studies evaluating the effects of several landscape metrics on the following services: pollination, pest control, water quality, disease control, and aesthetic value. We report the cumulative mean effect size $\left(\mathrm{E}_{++}\right)$, where the signal of the values is related to positive or negative influences.

Results Landscape complexity differentially influenced the provision of services. Particularly, the percentage of natural areas had an effect on natural enemies $\left(E_{++}=0.35\right)$, pollination $\left(E_{++}=0.41\right)$, and disease control $\left(\mathrm{E}_{++}=0.20\right)$, while the percentage of no-crop areas had an effect on water quality $\left(\mathrm{E}_{++}=0.42\right)$ and pest response $\left(\mathrm{E}_{++}=0.33\right)$. Furthermore, heterogeneity had an effect on aesthetic value $\left(\mathrm{E}_{++}=0.5\right)$ and water quality $\left(\mathrm{E}_{++}=-0.40\right)$. Moreover, landscape aggregation was important to explaining pollination $\left(\mathrm{E}_{++}=0.29\right)$ and water quality $\left(\mathrm{E}_{++}=0.35\right)$.

Conclusions The meta-analyses reinforce the importance of considering landscape structure in assessing ecosystem services for management purposes and decision-making. The magnitude of landscape effect varies according to the service being studied. Therefore, land managers must account for landscape composition and configuration in order to ensure the maintenance of services and adapt their approach to suit the focal service. 
Keywords Landscape metrics - Spatial patterns . Structure $\cdot$ Management $\cdot$ Complexity $\cdot$ Ecological benefits

\section{Introduction}

Landscape patterns emerge from the composition and configuration of its basic elements, and these patterns influence both ecological processes and ecosystem functions (Turner 2005). This also holds true for ecosystem services, which heavily depend on the health of these functions, and on the spatial interactions and flow between ecosystems and anthropogenic areas (Termorshuizen and Opdam 2009; Syrbe and Walz 2012). To identify target areas for conservation, restoration, or enhancement of ecosystem services, decision-makers must consider spatial contexts and landscape patterns. Undoubtedly, human population growth has increased the demand for high-quality multifunctional landscapes (DeClerck et al. 2016; Garbach et al. 2016), and created an urgent need for more practical and applicable information to guide efficient decision-making toward this end.

The recently introduced concept of 'landscape services' is an essential part of the emerging field sustainability science (Termorshuizen and Opdam 2009). Its primary difference from the 'ecosystem services' concept is the dependence of rendered services on spatial configuration and the influence of elements external to the ecosystem (Bastian et al. 2014). The landscape services concept encompasses the notion that a complete landscape can provide services through its multi-functionality and the processes that emerge from a set of unique ecosystems (Frank et al. 2012; Hodder et al. 2014), in both natural and human-modified habitats. This concept may prove useful for landscape planning, as the integration of ecological services could increase stakeholder participation, financial funding, and encompass working landscapes (Chan et al. 2006, 2011; Goldman et al. 2008; Carpenter et al. 2009; Duarte et al. 2016). However, integrating this concept into the planning process remains a global challenge (de Groot et al. 2010). To bypass this barrier, we must improve our understanding of how particular landscape patterns influence its services (Mitchell et al. 2015).
Landscape metrics are widely used in studies describing landscape patterns and their relationship to land use/land cover changes, biodiversity distribution, ecological processes, and ecosystem functions (Uuemaa et al. 2013). However, such analysis requires an awareness of the metrics' interrelationships and redundancy (Cushman et al. 2008) and their consistency for landscape management. For this purpose, aggregating landscape metrics into more general groups can facilitate stakeholders' understanding of landscape management (Cushman et al. 2008).

Previous studies have investigated how specific landscape patterns and features relate to the provision of ecosystem services (e.g., Bastian et al. 2014; Hodder et al. 2014; Chaplin-Kramer et al. 2015; Mitchell et al. 2015). In addition, recent reviews and quantitative analyses have begun synthesizing available knowledge in this area (Chaplin-Kramer et al. 2011; Garibaldi et al. 2011; Mitchell et al. 2013; Shackelford et al. 2013); however, the focus remains on relatively few services and landscape features (e.g., landscape complexity). This study aimed to thoroughly review and evaluate the relationship between several aspects of landscape patterns and certain ecosystem services. The primary target of this research was to provide support for more practical decisionmaking in landscape planning and management in order to ensure the maintenance of key landscape services.

Meta-analysis is the quantitative, scientific synthesis of research results aiming to achieve broad generalizations across a large number of study outcomes (Gurevitch et al. 2018). Meta-analyses have largely been used in ecology, evolution, and conservation biology (Gerstner et al. 2017) to estimate the overall magnitude of effects, and to identify factors that modulate such effects. In this meta-analytical review, we considered published studies that evaluated indicators of ecosystem services and the landscape patterns to maintain or influence their provision. We hypothesized that (1) landscape complexity would have a significant effect on the provision of all services evaluated due to its relationship with high multifunctionality; (2) for services related directly to fauna biodiversity and water quality, we expected a positive relationship with both landscape aggregation and habitat quantity; and (3) we expected landscape heterogeneity to affect cultural services, as cultural 
landscapes involve both natural and anthropogenic land types.

\section{Methods}

Study selection and inclusion criteria

For the present meta-analyses, we used three distinct approaches to conduct a systematic literature search aimed at collecting the most representative sample of existing primary research studies. First, we used articles already reviewed by Chaplin-Kramer et al. (2011; a meta-analysis of the effect of landscape complexity on pest control services), Garibaldi et al. (2011; a synthesis regarding landscape effects on the stability of pollination services), Shackelford et al. (2013; a meta-analysis of landscape and local effects on the abundance and richness of pollinators and natural enemies) and Uuemaa et al. (2013; a review of trends in the use of landscape metrics). We then performed an extensive search in the Web of Science database, using the keywords "landscape metrics," "landscape indexes," and "landscape indices" to complement the research by Uuemaa et al. (2013) which reviewed studies between 2000 and 2010 using the same keywords-by adding studies published between 2011 and 2016. Finally, we reviewed relevant articles provided in the reference lists of all previously selected studies.

The present study only considered studies that used landscape metrics related to empirical data of functions or ecological indicators that directly benefit human well-being. We did not consider habitat function for biodiversity, except when primary studies explicitly cited biodiversity as being (or potentially being) directly related to certain ecosystem services (e.g., pollination and pest control). Furthermore, we chose to exclude habitat function, as this is not the focus of the present research and several previous scientific works and reviews have already studied the effect of landscape patterns on biodiversity and its conservation (Fahrig 2003, 2017; Uuemaa et al. 2013).

In addition, we restricted our research to terrestrial landscapes in rural, agricultural, mixed rural-urban or natural habitats regions, thus excluding strictly urban or marine landscapes. One study inclusion criterion was the reporting of statistical parameters (e.g., r, F, $\chi^{2}$, Spearman-rho, $\mathrm{t}$ or $\mathrm{R}^{2}$, and sample size) on the relationship between at least one landscape metric and one landscape function, or the partial contribution of at least one landscape metric. In some cases, we extracted and carefully reanalyzed the original raw data. When primary studies reported data in figures, we digitized them and extracted raw data using the Image J software version 1.46 (Schneider et al. 2012).

\section{Landscape explanatory variables}

The present study used landscape complexity variables, primarily those related to increasing the amount, spatial heterogeneity, and landscape connectivity of natural and semi-natural areas as predictors for explaining ecosystem services. These explanatory variables were grouped into four major groups according to the patterns they measured: (a) percentage of natural areas; (b) percentage of non-crop areas; (c) landscape aggregation, which "refers to the tendency of patch types to be spatially aggregated; that is, to occur in large, aggregated or 'contagious' distributions" (MacGarigal et al. 2012); and (d) landscape heterogeneity, which refers to the degree of heterogeneity of landscape elements, including metrics such as diversity, evenness and richness indexes for natural and semi-natural land cover classes, and for the entire landscape (see example and metric definitions in MacGarigal et al. 2012; Fig. 1). Additionally, landscape aggregation was also subdivided into: (c1) landscape connectivity-metrics related to the proximity/connectance of landscape natural elements; and (c2) landscape fragmentation-metrics related to the number of patches, edges, and the isolation of natural and semi-natural areas. By using these groups, it is possible to provide greater detail regarding manageable landscape characteristics that affect ecosystem services. The analyses in the present study evaluated the landscape metrics described in Fig. 1. However, only the groups that had at least five independent comparisons were included in the meta-analyses. In relation to the landscape metrics of natural area fragmentation and percentage of crops, we used inverted values of the reported statistical data, as these metrics are considered inversely related to the positive ecological effects of landscape complexity. 


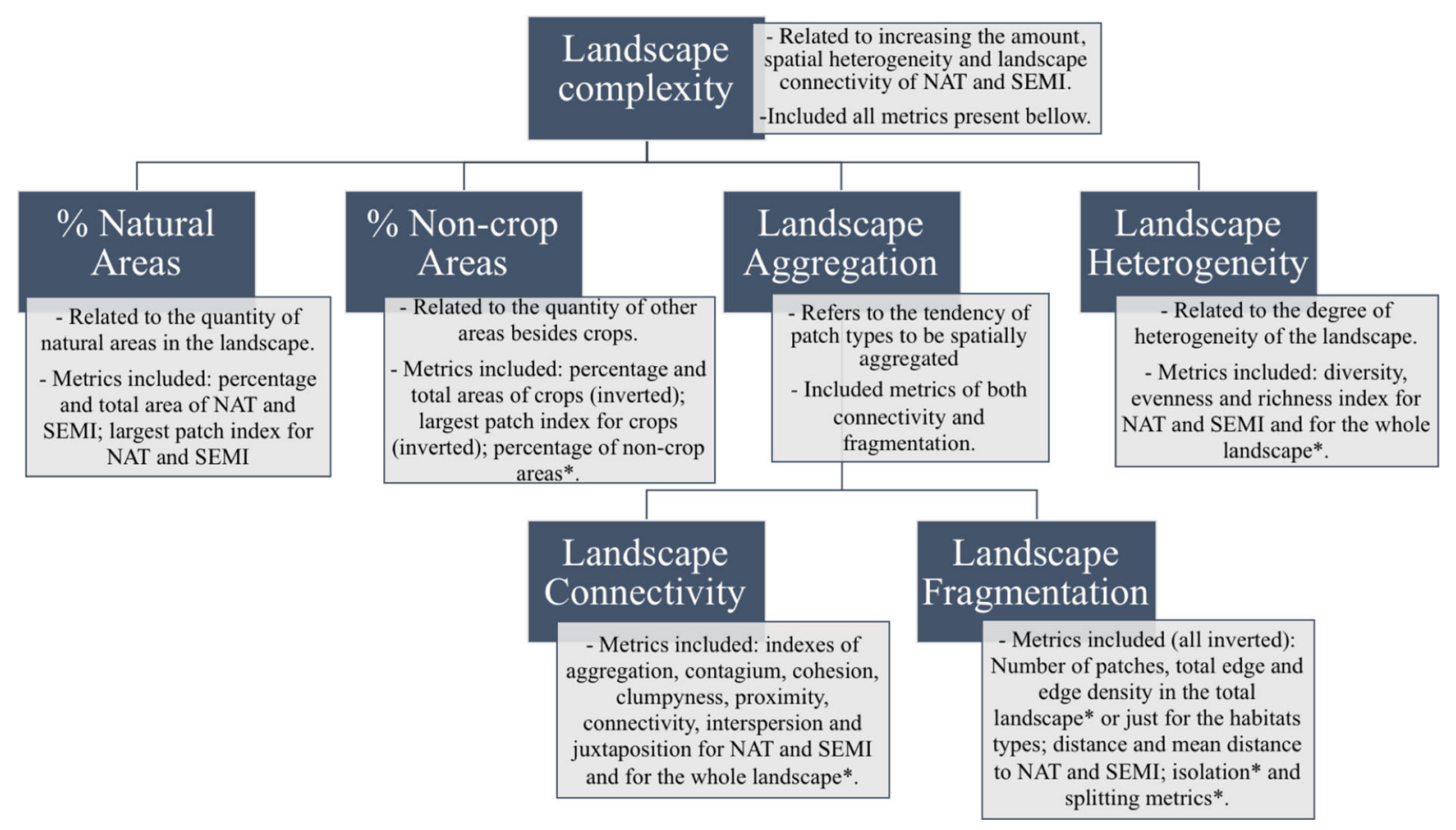

Fig. 1 A flowchart representing the landscape-metric groups and subgroups. Group names are in the dark gray boxes. Descriptions of each group and subgroup, with their related landscape metrics, are in the light gray boxes. NAT and SEMI

\section{Ecosystem service response variables}

Many ecosystem services related to water quality have been described by Keeler et al. (2012). Additionally, there is evidence to support landscape patterns influencing the provision of these services (Allan 2004). As response variables, we grouped several water functions, which are collectively referred to as "water quality-related services' in the present study. Furthermore, we followed the study of Keeler et al. (2012) and searched for articles reporting concentrations of nitrogen, phosphorus, and sediments (including suspended solids and turbidity) as indicators of water quality. Based on these findings, we then inverted the sign of results from the meta-analysis in order to understand the effects of landscape complexity on the water quality indicators more easily.

The same approach was utilized to assess the service of disease control. This involved searching for primary studies reporting indicators of loss of disease control, such as disease prevalence, host and vector abundances, and infection levels. After the metaanalysis, the sign of its results was then inverted to stand for natural and semi-natural areas, respectively. Descriptions for each landscape metric can be found in McGarigal et al. (2012). Asterisks at a landscape level, these metrics also account for anthropogenic (non-natural) areas

assess the effects of landscape metrics on disease control indicators. To assess the service of pest control, two contrasting approaches were used. The first approach measured pest response through indicators related to pest abundance, richness, and damage. The second approach measured natural enemies' response through indicators such as natural enemy abundance, richness, diversity, and direct effects on pest reduction. As a result, two types of indicators of the effects of landscape complexity on pest control were available: one related to service providers (natural enemies) and other to disservice providers (pests). We also evaluated the service of pollination of agricultural areas using the abundance, richness, diversity, and effects of pollinators as indicators, as well as the service of aesthetic value using indicators from landscape preference studies.

For studies that exhibited a multi-scale approach (e.g., concentric radii to determine different landscapes) or multiple sampling seasons, we chose the most predictive scale or period of the year (following Chaplin-Kramer et al. 2011; Shackelford et al. 2013). For primary studies yielding results in different years, 
we considered every year for which authors reported a change in land use/land cover. Furthermore, following Shackelford et al. (2013), the mean of reported effect sizes for multi-subgroups of taxa was used (for example, spider families and bee genera).

\section{Data analysis}

Pearson product-moment correlation coefficients (r) were used as a measure of effect size, weighted by sample sizes for the meta-analyses. When studies did not report $r$ values, the statistical results provided by the authors $\left(\mathrm{F}, \chi^{2}\right.$, Spearman-rho, $\mathrm{t}$ or $\mathrm{R}^{2}$ ) were converted to the correlation coefficient ( $\mathrm{r}$ ). All $\mathrm{r}$ values were then converted into Fisher's Z (Rosenthal and DiMatteo 2001), as follows:

$z=\frac{1}{2} \ln \left(\frac{1+r}{1-r}\right)$

and the asymptotic variance of $\mathrm{z}$ was calculated as:

$v_{z}=\frac{1}{n-3}$

where $n$ represents the sample size. Fisher's $\mathrm{z}$ transforms ranges from $-\infty$ to $+\infty$, where negative values of $\mathrm{z}$ represent a negative effect, positive values of $\mathrm{z}$ represent a positive effect, and $\mathrm{z}=0$ represents no effect. We calculated the $95 \%$ confidence intervals around a cumulative effect size for each variable of interest. Moreover, we considered estimates of the true effect size to be significant if confidence intervals did not overlap with zero. We conducted all analyses using MetaWin software version 2.0 (Rosenberg et al. 2000). In addition, we used mixed models to calculate the cumulative effect sizes $\left(\mathrm{E}_{++}\right)$for each group of landscape metrics, assuming that studies within a group share a common mean effect and that both random variation and sampling variation exists within a group. Then, the average of $\mathrm{z}$ values was weighted by the inverse of their variance.

Once the effect sizes for each landscape metric and service were calculated, we examined total and group heterogeneity among effects by partitioning variance within groups and testing whether categorical landscape groups were homogeneous with respect to effect sizes. We used the Q-statistic, and total heterogeneity (QT) was partitioned into within-class heterogeneity $(\mathrm{QW})$ and between-class heterogeneity (QB). Total heterogeneity (QT) was calculated as QT $=\Sigma \mathrm{w}_{\mathrm{i}}$ $\left(E_{i}-E_{++}\right)^{2}$, where $w_{i}$ is the reciprocal of the variance, $E_{i}$ is the effect size for each study, and $\mathrm{E}_{++}$is the cumulative effect size for the set of studies under evaluation. QT follows a Chi square distribution with $\mathrm{k}-1$ degrees of freedom. Since we based our analyses on published studies alone, we checked for publication bias and the file-drawer problem by calculating Rosenthal's fail-safe number (Rosenthal and DiMatteo 2001). This number determines the hypothetical number of missing or unpublished studies that, if added, would change the effects from significant to non-significant. If this number is sufficiently high (larger than $5 \mathrm{k}+10$, where $\mathrm{k}=$ number of independent comparisons), the results can be considered robust despite publication bias.

\section{Results}

A total of 121 articles fit the inclusion criteria and were used in the meta-analyses. Following a critical review and evaluation of data available for analysis, the services described in the Ecosystem Services Response Variables section were those that data could be located for, which included: (a) water quality, (b) disease control, (c) loss of pest control by increase in pest response, (d) pest control by increase of natural enemies' response, (e) pollination, and (f) aesthetic value.

Studies addressing natural enemies' response represented c.a. $30 \%$ of the articles included in the present review ( $\mathrm{N}=36$ articles), while $28 \%$ concerned water quality $(\mathrm{N}=34)$, and $21 \%$ evaluated pollination services $(\mathrm{N}=26)$, which was followed by pest response $(\mathrm{N}=11)$, disease control $(\mathrm{N}=8)$, and aesthetic value $(\mathrm{N}=6)$. These selected studies generated 90, 327, 62, 40, 41, and 23 independent comparisons, respectively. Additional details regarding the primary data used for the present analyses is located in the supplementary material (Online Resource 1). Also, landscape complexity significantly influenced all services evaluated in this research, with the exception of disease control. The main results of each evaluated service are presented as follows:

- Water quality Our results indicate an increase of nearly 30\% [Cumulative mean effect size $\left(\mathrm{E}_{++}\right)=0.29, \quad$ Confidence interval (CI) 
0.24-0.32, degrees of freedom $(\mathrm{df})=327]$, with an increase in landscape complexity (Fig. 2a). Furthermore, water quality varied significantly when various aspects of landscape metrics were evaluated $(\mathrm{QB}=86.89$, df $=3, \mathrm{P}<0.001$; Table 1$)$, and the strongest (and most positive) effect was observed for the percentage of non-crop areas $\left(\mathrm{E}_{++}=0.42, \mathrm{CI} 0.35-0.49, \mathrm{df}=120\right)$. Landscape connectivity also positively influenced water quality $\left(\mathrm{E}_{++}=0.35\right.$, CI $\left.0.20-0.50, \mathrm{df}=32\right)$, though landscape fragmentation did not $\left(\mathrm{E}_{++}=0.06\right.$, CI -0.08 to $0.20, \mathrm{df}=35$ ). Landscape heterogeneity exhibited a significant and negative effect on water quality $\left(\mathrm{E}_{++}=-0.40\right.$, CI -0.58 to -0.23 ,

(a)

Water quality

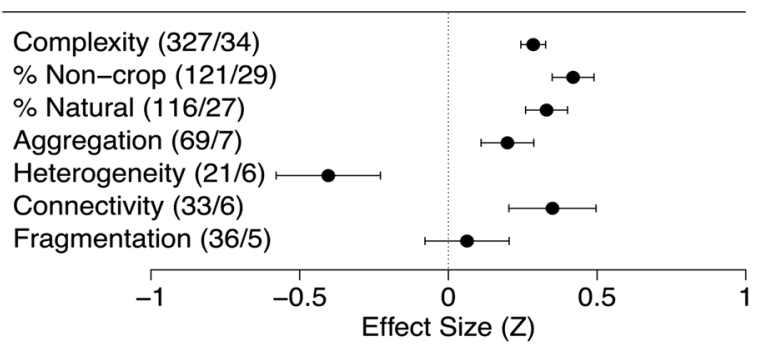

(b)

Disease control

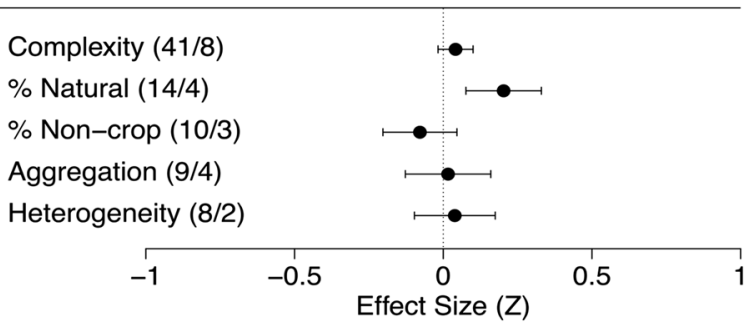

(c)

Pest response

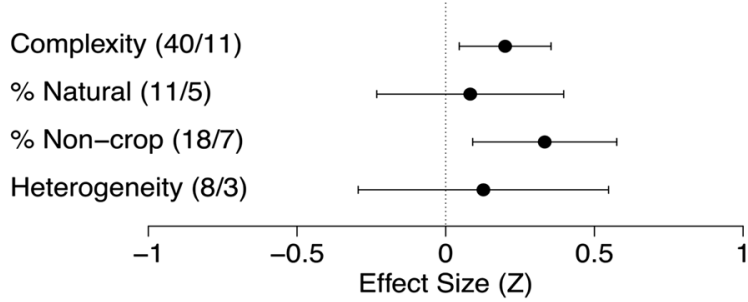

Fig. 2 Effects of the selected landscape-metric groups (see Fig. 1 for more information regarding the groups) on the following ecosystem services: a water quality, b disease control, c pest response, $\mathbf{d}$ natural enemies' response, e pollination, and $\mathrm{df}=20$ ), indicating that heterogeneous matrices of non-natural areas, such as agricultural, urban, commercial and industrial areas, may decrease the effects of this service. Amongst the articles analyzed, approximately $90 \%$ evaluated water quality in landscapes that included a very heterogeneous matrix of non-natural areas within cited land use classes. In summary, these results suggest that an increase in landscape characteristics such as non-crop areas, the percentage of natural habitat, and landscape aggregation enhances the provision of services related to water quality.

- Disease control The effect of landscape complexity on this service was slightly positive, though not

(d)

\section{Natural enemies' response}

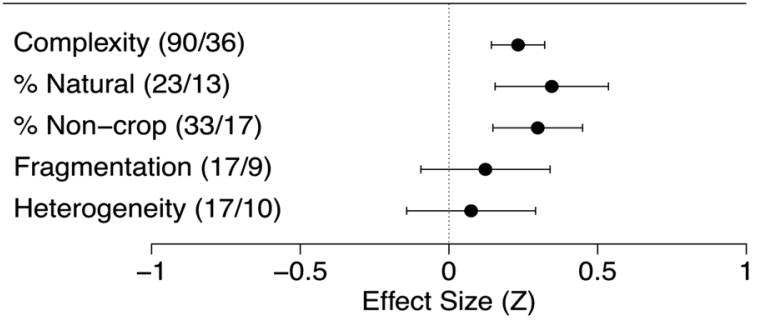

(e)

\section{Pollination}

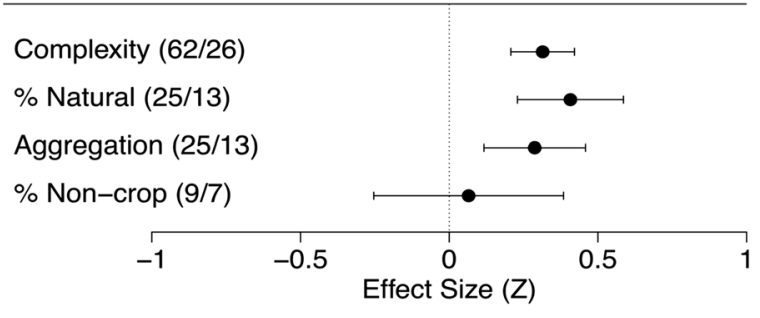

(f)

\section{Aesthetic value}

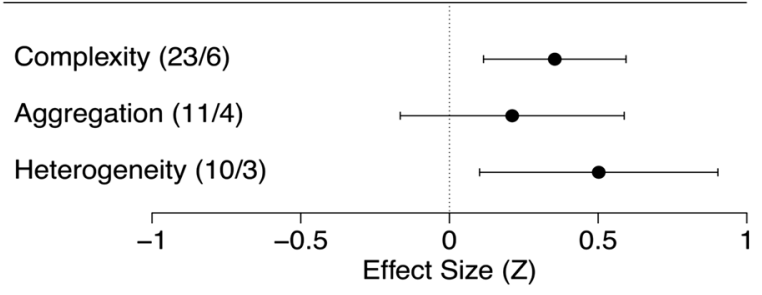

f aesthetic value. Values in parentheses denote the total number of independent comparisons/total number of primary studies, respectively. Lines indicate the $95 \%$ confidence interval around the effect size for each group 
Table 1 Results from heterogeneity analysis and Rosenthal's fail-safe number following a meta-analysis regarding the effect of landscape patterns on ecosystem services

\begin{tabular}{lllllll}
\hline & Ecosystem services & & & \\
\cline { 2 - 7 } & Water quality & Disease control & Pest response & Natural enemies & Pollination & Aesthetic value \\
\hline$Q B(P$ value $)$ & $86.89(\ll 0.001)$ & $12.49(0.006)$ & $2.45(0.48)$ & $5.85(0.12)$ & $5.61(0.13)$ & $1.43(0.49)$ \\
$Q W(P$ value $)$ & $509.68(\ll 0.001)$ & $142.11(\ll 0.001)$ & $35.12(0.51)$ & $95.26(0.23)$ & $89.82(0.004)$ & $19.83(0.47)$ \\
$Q T(P$ value $)$ & $596.56(\ll 0.001)$ & $154.60(\ll 0.001)$ & $37.57(0.53)$ & $101.11(0.18)$ & $95.43(0.003)$ & $21.25(0.50)$ \\
Fail-safe number & 21,094 & 56 & 65 & 850 & 825 & 56 \\
\hline
\end{tabular}

Using Q statistics, total heterogeneity (QT) was partitioned into within-class heterogeneity (QW) and between-class heterogeneity (QB) following a Chi square distribution with $\mathrm{k}-1$ degrees of freedom (df). The fail-safe number was calculated as NR $=([\Sigma \mathrm{z}$ $\left.(\mathrm{pi})]^{2} / \mathrm{z}_{\alpha}^{2}\right)-\mathrm{n}$, where $\mathrm{z}$ is the score of the normal distribution, $\mathrm{z}_{\alpha}$ is the $\mathrm{z}$ score associated with the chosen alpha (0.05), and $\mathrm{n}$ is the number of studies

significant $\left(\mathrm{E}_{++}=0.04, \mathrm{CI}-0.01\right.$ to $0.1, \mathrm{df}=$ 40). Amongst the landscape metrics evaluated, the percentage of natural areas in the landscape had a significant and positive effect on this service (Fig. 2b), enhancing disease control by approximately $20 \%\left(\mathrm{E}_{++}=0.20\right.$, CI $\left.0.07-0.33, \mathrm{df}=13\right)$ in areas with higher percentages of natural habitats. However, fail-safe values indicated that results were not robust (Table 1) and should be interpreted with caution. Furthermore, among the independent comparisons evaluated for disease control, heterogeneity analyses remained significant $(\mathrm{QT}=154.60, P<0.0001)$, even after partitioning the mean effect into different landscape metrics.

- Pest response An evaluation of pest response data (Fig. 2c) indicated that the percentage of non-crop areas increased pest response by nearly 35\% $\left(\mathrm{E}_{++}=0.33\right.$, CI 0.09 to 0.57 , df $\left.=17\right)$, though the percentage of natural areas surrounding agricultural areas did not influence the loss of pest control $\left(\mathrm{E}_{++}=0.08, \mathrm{CI}-0.23\right.$ to $\left.0.40, \mathrm{df}=10\right)$.

- Natural enemies' response With regard to pest control services by natural enemies, we determined that an increase in landscape complexity enhanced natural enemies' response by nearly $25 \% \quad\left(\mathrm{E}_{++}=0.23, \quad\right.$ CI $0.14-0.32, \quad \mathrm{df}=89$; Fig. 2d). However, although this service was influenced homogeneously within different landscape-metric groups $(\mathrm{QB}=5.85, P=0.11$, df $=$ 3; Table 1), an increase in the percentage of natural habitats $\left(\mathrm{E}_{++}=0.35\right.$, CI $0.15-0.54, \mathrm{df}=$ $22)$ and non-crop areas $\left(\mathrm{E}_{++}=0.30, \mathrm{CI}\right.$
0.14-0.44, df = 32) had the strongest effects on natural enemies' responses.

- Pollination This service was $31 \%$ higher in complex landscapes $\left(\mathrm{E}_{++}=0.31\right.$, CI $0.21-0.42$, $\mathrm{df}=61$; Fig. 2e). The percentage of natural habitats increased this service by $41 \%\left(\mathrm{E}_{++}=0.41, \mathrm{CI}\right.$ $0.22-0.58$, df $=24)$, whereas landscape aggregation increased pollination by $29 \%\left(\mathrm{E}_{++}=0.29\right.$, CI $0.11-0.45$, df =24). However, the effects of landscape-metric groups similarly influenced pollination $(\mathrm{QB}=5.61, P=0.13, \mathrm{df}=3$; Table 1$)$.

- Aesthetic value Relatively few studies evaluated aesthetic value (i.e., the perception of landscape as a cultural service) from a landscape perspective. Although this service increased due to landscape aspects such as heterogeneity $\left(\mathrm{E}_{++}=0.50\right.$, CI 0.10-0.90, df $=9$; Fig. 2f), it did not differ amongst landscape-metric groups $(\mathrm{QB}=1.42$, $P=0.49)$.

Evaluation of publication bias

For the majority of analyzed effects, fail-safe values were greater than $5 \mathrm{k}+10$ (where $\mathrm{k}$ is the number of independent comparisons) (Table 1). For water quality, natural enemies' response, and pollination services, these values were relatively large, indicating the robustness of results on the mean effect, which suggests the absence of publication bias. Scatter plots of effect sizes against sample sizes for all services separately exhibited a typical funnel shape (Online Resource 2), indicating that studies with small sample sizes had a large dispersion of effect sizes around the 
true effect value, whereas studies with larger sample sizes tended to possess effect sizes around the true mean value.

\section{Discussion}

We determined that specific groups of landscape patterns influenced the provision of ecosystem services differently. Composition landscape metrics, as the percentage of natural or no-crop areas and landscape heterogeneity, influenced all services evaluated in the present research, while configuration metrics such as landscape aggregation influenced two services: pollination and water quality. Our hypothesis regarding landscape complexity was confirmed for water quality, pollination, both pest control indicators, and aesthetic value. Therefore, the role of landscape complexity on increasing the provision of different services suggests that the restoration of natural areas using a land-sharing perspective could be important for the provision of multi-ecosystem functions, which corroborates with results from Barral et al. (2015).

We highlight that water quality can correspond to several different services (Keeler et al. 2012); for example, safe drinking water, commercial fishing, and recreational benefits, among others. A reduction in agricultural areas generally increases water quality through the reduction of fertilizers and pesticides in water bodies. Moreover, increased areas of natural vegetation results in increased soil nutrients, as well as decreased erosion. In the context of riverscapes, the importance of increased connectivity, shown in this study, is due to increased natural riparian vegetation (Allan 2004). Therefore, restoration programs should prioritize riparian areas in order to retain this set of ecosystem services.

Notably, both water quality and pest control by natural enemies' indicators exhibited a trade-off with food production services, as measured by the percentage of crop area. However, landowners and society could benefit from an increase in natural areas in rural regions, which consequently carries improved ecosystem services. For example, landowners could benefit from restoration strategies that increase habitat for natural enemies on their lands (Chaplin-Kramer et al. 2011), or water for irrigation of their crops. Therefore, land managers should consider the creation of mechanisms that lead to greater landowner cooperation on actions that improve landscape conservation and the provision of desired ecosystem services (Goldman and Tallis 2009).

This study also revealed that the reduction of crop areas (or increase in the non-crop percentage) could increase the loss of pest control due to greater pest abundance, richness, and/or damage. This study follows Tscharntke et al.'s (2016) hypotheses to this apparent contradiction, which stated that "the relative importance of natural habitats for biocontrol can vary dramatically depending on type of crop, pest, predator, land management, and landscape structure". For example, many primary studies included in our review did not differentiate between organic or conventional agricultural strategies, or did not report if natural enemies were present in the study region. ChaplinKramer et al. (2011) determined that neither the percentage of natural non-crop vegetation nor the percentage of crops has significant effects on pest responses.

Similar to findings by Shackelford et al. (2013), landscape complexity increased pollination service in the present study. This increase was primarily due to the percentage of natural areas, but also due to the positive relationship with landscape aggregation. Therefore, landscape managers should consider both restoration approaches in landscape planning processes for regions with naturally pollinated crops. Ricketts et al. (2008) and Garibaldi et al. (2011) also determined that the distance to habitat influences pollination services. Combined, these findings lend support to the theoretical design proposed by Brosi et al. (2008), who suggested that, in order to increase pollination services in agricultural landscapes, there should be areas large enough to sustain pollinator populations, with other smaller natural areas within the crop matrix with distances not much greater than pollinators' foraging distances. Although we observed a significant effect of aggregation metrics on one fauna-related service (pollination), this did not fully confirm our primary hypotheses. However, a recent review by Fahrig (2017) suggests that ecological responses to fragmentation typically have other influences aside from landscape structure.

With regard to disease control, although landscape configuration has an important and significant impact, the determined fail-safe value was insufficiently robust. Additionally, articles related to disease control services were difficult to locate using our research 
method. Relatively few studies evaluated the impacts of landscape structure on epidemiological processes, though other reviews indicate that the integration of landscape ecological and epidemiological knowledge can be fruitful (e.g., Elliott and Wartenberg 2004; Graham et al. 2005; Ostfeld et al. 2005; Killilea et al. 2008). As disease risk and incidence are related to the communities and dynamics of their pathogens, vectors, reservoirs or hosts, the configuration and composition of landscapes has the potential to influence them, making this type of information useful for landscape managers in regions with high disease risk (Prist et al. 2017).

Notably, landscape heterogeneity had an important effect on the perception of aesthetic value reported by the interviewees in the selected studies, which confirms our hypothesis. However, due to the small sample size available (only six studies), this result was insufficiently robust. Although many other articles have studied this landscape service, their data was not adequately reported for inclusion in our meta-analysis. However, the conclusions of these excluded articles are similar in that landscape heterogeneity is important to peoples' perception of aesthetic value (e.g., Dramstad et al. 2001; De Groot and Van Den Born 2003; Franco et al. 2003; Sang et al. 2008; Herbst et al. 2009; Ode and Miller 2011; Frank et al. 2013; Surová et al. 2014). Furthermore, increased aesthetic value has the potential to increase satisfaction through regional tourism, and offers other spiritual and cultural benefits for society.

Overall, these meta-analyses reinforce the importance of considering landscape structure on assessing ecosystem services for management purposes and decision-making. The magnitude of landscape effect varies according to the landscape metrics and services. Therefore, the results presented in the present study advance our understanding of landscape patterns, and offer guidance for land management activities regarding the provision of landscape services. Land managers must account for landscape composition and configuration in ensuring that services are maintained, and adapt their approach depending upon the relevant focal services.

Acknowledgements We would like to thank all LEC-UFMG and LEEC-UNESP members for their various forms of contribution, especially Rafaela Silva, Julia Assis and Arleu Viana for their support during this work. We thank Coordination for the Improvement of Higher Education Personnel (CAPES) and National Council for Scientific and Technological Development (CNPq) for the G.T. Duarte and P.M. Santos scholarships. M.C. Ribeiro is funded by CNPq (Grant Nos. 312,045/2013-1 and 312292/2016-3), PROCAD/CAPES (Project \# 88881.068425/2014-01) and The São Paulo Research Foundation (FAPESP - Grant 2013/50421-2). T. Cornelissen is funded by CNPq (Grant 307210-2016-2). A. Paglia is funded by CAPES, CNPq and FAPEMIG. We also thank two anonymous reviewers for their valuable comments and suggestions.

\section{References}

Allan JD (2004) Landscapes and riverscapes: the influence of land use on stream ecosystems. Annu Rev Ecol Evol Syst 35:257-284

Barral MP, Benayas JMR, Meli P, Maceira NO (2015) Quantifying the impacts of ecological restoration on biodiversity and ecosystem services in agroecosystems: a global metaanalysis. Agric Ecosyst Environ 202:223-231

Bastian O, Grunewald K, Syrbe RU, Walz U, Wende W (2014) Landscape services: the concept and its practical relevance. Landscape Ecol 29(9):1463-1479

Brosi BJ, Armsworth PR, Daily GC (2008) Optimal design of agricultural landscapes for pollination services. Conserv Lett 1:27-36

Carpenter SR, Mooney HA, Agard J, Capistrano D, DeFries RS, Díaz S, Dietz T, Duraiappah AK, Oteng-Yeboah A, Pereira HM, Perrings C (2009) Science for managing ecosystem services: beyond the Millennium Ecosystem Assessment. Proc Natl Acad Sci USA 106(5):1305-1312

Chan KMA, Hoshizaki L, Klinkenberg B (2011) Ecosystem services in conservation planning: targeted benefits vs. cobenefits or costs? PLoS ONE 6:e24378

Chan KM, Shaw MR, Cameron DR, Underwood EC, Daily GC (2006) Conservation planning for ecosystem services. PLoS Biol 4(11):e379

Chaplin-Kramer R, O’Rourke ME, Blitzer EJ, Kremen C (2011) A meta-analysis of crop pest and natural enemy response to landscape complexity. Ecol Lett 14:922-932

Chaplin-Kramer R, Sharp RP, Mandle L, Sim S, Johnson J, Butnar I, Canals LM, Eichelberger BA, Ramler I, Mueller C, McLachlan N (2015) Spatial patterns of agricultural expansion determine impacts on biodiversity and carbon storage. Proceedings of the National Academy of Sciences 112(24):7402-7407

Cushman SA, McGarigal K, Neel MC (2008) Parsimony in landscape metrics: strength, universality, and consistency. Ecol Indic 8:691-703

de Groot RS, Alkemade R, Braat L, Hein L, Willemen L (2010) Challenges in integrating the concept of ecosystem services and values in landscape planning, management and decision making. Ecol Complex 7:260-272

de Groot WT, Van Den Born RJG (2003) Visions of nature and landscape type preferences: an exploration in The Netherlands. Landsc Urban Plan 63:127-138

DeClerck FAJ, Jones SK, Attwood S, Bossio D, Girvetz E, Chaplin-Kramer B, Enfors E, Fremier AK, Gordon LJ, Kizito F, Noriega IL (2016) Agricultural ecosystems and 
their services: the vanguard of sustainability? Curr Opin Environ Sustain 23:92-99

Dramstad WE, Fry G, Fjellstad WJ, Skar B, Helliksen W, Sollund ML, Tveit MS, Geelmuyden AK, Framstad E (2001) Integrating landscape-based values-Norwegian monitoring of agricultural landscapes. Landsc Urban Plan 57(3-4):257-268

Duarte GT, Ribeiro MC, Paglia AP (2016) Ecosystem services modeling as a tool for defining priority areas for conservation. PLoS ONE 11:e0154573

Elliott P, Wartenberg D (2004) Spatial epidemiology: current approaches and future challenges. Environ Health Perspect 112:998-1006

Fahrig L (2003) Effects of habitat fragmentation on biodiversity. Annu Rev Ecol Syst 34:487-515

Fahrig L (2017) Ecological responses to habitat fragmentation per se. Annu Rev Ecol Evol Syst 48:1-45

Franco D, Franco D, Mannino I, Zanetto G (2003) The impact of agroforestry networks on scenic beauty estimation the role of a landscape ecological network on a socio-cultural process. Landsc Urban Plan 62:119-138

Frank S, Fürst C, Koschke L, Makeschin F (2012) A contribution towards a transfer of the ecosystem service concept to landscape planning using landscape metrics. Ecol Indic 21:30-38

Frank S, Fürst C, Koschke L, Witt A, Makeschin F (2013) Assessment of landscape aesthetics-validation of a landscape metrics-based assessment by visual estimation of the scenic beauty. Ecol Indic 32:222-231

Garbach K, Milder JC, DeClerck FAJ, Montenegro M, Driscoll L, Gemmill-Herren B (2016) Examining multi-functionality for crop yield and ecosystem services in five systems of agroecological intensification. Int $\mathrm{J}$ Agric Sustain 5903:1-22

Garibaldi LA, Steffan-Dewenter I, Kremen C, Morales JM, Bommarco R, Cunningham SA, Carvalheiro LG, Chacoff NP, Dudenhöffer JH, Greenleaf SS, Holzschuh A (2011) Stability of pollination services decreases with isolation from natural areas despite honey bee visits. Ecol Lett 14(10):1062-1072

Gerstner K, Moreno-Mateos D, Gurevitch J, Beckmann M, Kambach S, Jones HP, Seppelt R (2017) Will your paper be used in a meta-analysis? Make the reach of your research broader and longer lasting. Methods in Ecology and Evolution 8(6):777-784

Goldman RL, Tallis H (2009) A critical analysis of ecosystem services as a tool in conservation projects: the possible perils, the promises and the partnerships. Ann N Y Acad Sci 1162:63-78

Goldman RL, Tallis H, Kareiva P, Daily GC (2008) Field evidence that ecosystem service projects support biodiversity and diversify options. Proc Natl Acad Sci U S A 105:9445-9448

Graham AJ, Danson FM, Craig PS (2005) Ecological epidemiology: the role of landscape structure in the transmission risk of the fox tapeworm Echinococcus multicularis (Leukart 1863) (Cestoda: Cyclophyllidea: Taeniidae). Prog Phys Geogr 29:77-91

Gurevitch J, Koricheva J, Nakagawa S, Stewart G (2018) Metaanalysis and the science of research synthesis. Nature 555:175-182
Herbst H, Förster M, Kleinschmit B (2009) Contribution of landscape metrics to the assessment of scenic quality - the example of the landscape structure plan Havelland/Germany. Landsc Online 10:1-17

Hodder KH, Newton AC, Cantarello E, Perrella L (2014) Does landscape-scale conservation management enhance the provision of ecosystem services? Int J Biodivers Sci Ecosyst Serv Manag 10:71-83

Keeler BL, Polasky S, Brauman KA, Johnson KA, Finlay JC, O’Neill A, Kovacs K, Dalzell B (2012) Linking water quality and well-being for improved assessment and valuation of ecosystem services. Proc Natl Acad Sci USA 109(45):18619-18624

Killilea ME, Swei A, Lane RS, Briggs CJ, Ostfeld RS (2008) Spatial dynamics of Lyme disease: a review. EcoHealth 5:167-195

McGarigal K, Cushman SA, Ene E (2012) FRAGSTATS v4: Spatial Pattern Analysis Program for Categorical and Continuous Maps. Computer software program produced by the authors at the University of Massachusetts, Amherst. http://www.umass.edu/landeco/research/fragstats/ fragstats.html. Accessed 27 April 2018

Mitchell MGE, Bennett EM, Gonzalez A (2013) Linking landscape connectivity and ecosystem service provision: current knowledge and research gaps. Ecosystems 16:894-908

Mitchell MG, Suarez-Castro AF, Martinez-Harms M, Maron M, McAlpine C, Gaston KJ, Johansen K, Rhodes JR (2015) Reframing landscape fragmentation's effects on ecosystem services. Trends Ecol Evol 30(4):190-198

Ode A, Miller D (2011) Analysing the relationship between indicators of landscape complexity and preference. Environ Plan B Plan Des 38:24-38.

Ostfeld RS, Glass GE, Keesing F (2005) Spatial epidemiology: an emerging (or re-emerging) discipline. Trends Ecol Evol 20:328-336.

Prist PR, de Muylaert R, Prado A, Umetsu F, Riberio MC, Pardini R, Metzger JP (2017) Using different proxies to predict hantavirus disease risk in São Paulo state, Brazil. Oecologia Aust 21:42-53.

Ricketts TH, Regetz J, Steffan-Dewenter I, Cunningham SA, Kremen C, Bogdanski A, Gemmill-Herren B, Greenleaf SS, Klein AM, Mayfield MM, Morandin LA (2008) Landscape effects on crop pollination services: are there general patterns? Ecol Lett 11(5):499-515

Rosenberg MS, Adams DC, Gurevitch J (2000) Metawin Statistical Software for Meta-analysis. Version 2.0. Sinauer Associates, Inc, Sunderland, Massachusetts

Rosenthal R, DiMatteo MR (2001) Meta-analysis: recent developments in quantitative methods for literature reviews. Annu Rev Psychol 52:59-82.

Sang N, Miller D, Ode A (2008) Landscape metrics and visual topology in the analysis of landscape preference. Environ Plan B Plan Des 35:504-520.

Schneider CA, Rasband WS, Eliceiri KW (2012) NIH Image to ImageJ: 25 years of image analysis. Nat Methods 9:671-675.

Shackelford G, Steward PR, Benton TG, Kunin WE, Potts SG, Biesmeijer JC, Sait SM (2013) Comparison of pollinators and natural enemies: a meta-analysis of landscape and local effects on abundance and richness in crops. Biol Rev 88(4):1002-1021 
Surová D, Pinto-correia T, Marusak R (2014) Visual complexity and the montado do matter: landscape pattern preferences of user groups in Alentejo, Portugal. Ann For Sci 71:15-24.

Syrbe RU, Walz U (2012) Spatial indicators for the assessment of ecosystem services: providing, benefiting and connecting areas and landscape metrics. Ecol Indic 21:80-88.

Termorshuizen JW, Opdam P (2009) Landscape services as a bridge between landscape ecology and sustainable development. Landscape Ecol 24:1037-1052
Tscharntke T, Karp DS, Chaplin-Kramer R, Batáry P, DeClerck F, Gratton C, Hunt L, Ives A, Jonsson M, Larsen A, Martin EA (2016) When natural habitat fails to enhance biological pest control-Five hypotheses. Biol Conserv 204:449-458

Turner MG (2005) Landscape ecology: what is the state of the science? Annu Rev Ecol Evol Syst 36:319-344

Uuemaa E, Mander Ü, Marja R (2013) Trends in the use of landscape spatial metrics as landscape indicators: a review. Ecol Indic 28:100-106 